\title{
ИЗМЕНЕНИЕ ФИЗИОЛОГИЧЕСКИХ И МОРФОЛОГИЧЕСКИХ ПОКАЗАТЕЛЕЙ КАЧЕСТВА СПЕРМЫ У СЕВЕРНЫХ ОЛЕНЕЙ (Rangifer tarandus) ПРИ КРИОКОНСЕРВАЦИИ
}

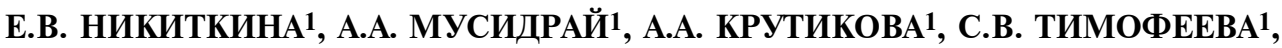 \\ К.В. ПЛЕМЯШОВ 1 , В.В. ГОНЧАРОВ ${ }^{2}$, С.В. ШАБУНИН ${ }^{3}$
}

Современные репродуктивные технологии позволяют бессрочно сохранять и рационально использовать генофонд исчезающих видов животных, создавать конкурентоспособные селекционные формы. В оленеводстве метод криоконсервации спермы практически не разработан. Суровые условия Арктики усложняют процесс получения спермы северных оленей (Rangifer tarandus) - животных с яркой сезонностью размножения. Гон у них проходит осенью, в течение месяца. Только в этот период можно получить сперму. После гона сперматогенез останавливается. Целью нашей работы была оценка изменения физиологических и морфологических показателей качества спермы северных оленей в процессе криоконсервации. Сперму от северных оленей получали с помощью электроэякулятора или посредством вымывания из придатков семенников. После оценки качества эякулированного и эпидидимального семени (объем, общая и прогрессивная подвижность и концентрация сперматозоидов) сперму разбавляли в среде Steridyl («Minitüb $\mathrm{GmbH»,} \mathrm{Германия)} \mathrm{до} \mathrm{конечной} \mathrm{концентрации} 100$ млн/мл, фасовали в соломинки по 0,25 мл и охлаждали до $5^{\circ} \mathrm{C}$ в течение 120 мин. После охлаждения и эквилибрации соломинки выдерживали в парах жидкого азота на поплавке при температуре $-110{ }^{\circ} \mathrm{C}$ в течение 12 мин и затем опускали в жидкий азот. Сперму размораживали при $37^{\circ} \mathrm{C}$. Первичная оценка эякулированной спермы показала, что средний объем эякулята составлял 0,5 $\pm 0,08$ мл, концентрация $-0,520 \pm 0,069$

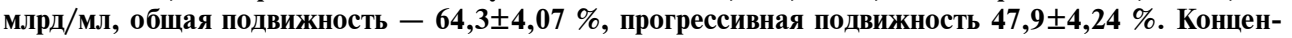
трация эпидидимальных спермиев была в среднем $0,260 \pm 0,078$ млрд/мл, общая и прогрессивная подвижность - соответственно 43,6 $\pm 8,49$ и $20,8 \pm 5,25 \%$. После криоконсервации общая подвижность снизилась в среднем на 41,9 $\pm 5,38 \%$, прогрессивная - на 36,8 $\pm 5,29 \%$. Сперматозоиды в $42 \%$ эякулятов теряли более 50 \% общей подвижности. В некоторых образцах наблюдалась полная потеря подвижности после замораживания, в некоторых изменения были незначительными. Большая изменчивость по снижению подвижности клеток наблюдалась как в эякулированной, так и в эпидидимальной сперме. Клетки эпидидимальной спермы имели более высокую подвижность после замораживания по сравнению с эякулированной, однако в эпидидимальной сперме наблюдалось больше нарушений в характере движения сперматозоидов. Анализ морфологии сперматозоидов показал, что в сперме северных оленей в сравнении с другими видами животных повышена доля сперматозоидов со сморщенной или отсутствующей акросомой - в среднем 6,9 $\pm 0,76 \%$. Значительного увеличения повреждений в области хвоста, шейки сперматозоидов и акросом после замораживания не наблюдалось. Количество клеток с повреждениями хвоста и шейки увеличилось в среднем на 4,2 $\pm 1,05 \%$, акросом - на 2,5 $\pm 0,35 \%$. Высокая изменчивость наблюдалась по увеличению повреждений плазматических мембран сперматозоидов (в среднем на 10,9 $\pm 5,02 \%)$. Такая вариабельность обусловлена разной криоустойчивостью спермы оленей и индивидуальной изменчивостью эякулятов. Достоверной разницы по изменениям физиологических и морфологических показателей качества спермы северных оленей после криоконсервации между эякулированной и эпидидимальной спермой выявлено не было. Таким образом, наиболышим изменениям при криоконсервации спермы северного оленя подвергается двигательная активность клеток, а также целостность мембран, что необходимо учитывать при оптимизации состава разбавителей и протокола криоконсервации.

Ключевые слова: Rangifer tarandus, северные олени, криоконсервация, подвижность сперматозоидов, акросомы, клеточные мембраны.

В Российской Федерации насчитывается около 2 млн диких и домашних северных оленей (Rangifer tarandus), ареал обитания которых занимает более половины территории страны. Для коренных народов Арктики оленеводство стало основной отраслью ведения хозяйства. Оленина это диетический продукт с высоким содержанием важных микроэлементов и витаминов. Совершенствование методов племенной работы, направленных на улучшение мясной продуктивности, - актуальная проблема разведения и селекции оленей в России (1). Существующие методы не обеспе-

* Работа выполнена при финансовой поддержке РНФ, проект № 17-16-01023. 
чивают нужные темпы роста производства оленеводческой продукции (1, 2). Кроме того, активное освоение Арктики привело к изменению климата, сокращению пастбищ и, как следствие, уменьшению численности домашних и диких северных оленей (3-5).

Современные репродуктивные технологии позволяют бессрочно сохранять и использовать генофонд исчезающих видов, проводить интенсивную селекцию и отбор лучших особей. Однако в оленеводстве эти технологии еще не нашли широкого применения (6-8). Высокая стоимость и сложность перевозки оленей в условиях Севера, а также неблагоприятный прогноз при акклиматизации самцов обусловливают необходимость разработки методов криоконсервирования семени северного оленя и создания криобанка спермы. Использование такой спермы позволит обмениваться генетическим материалом между отдаленными районами Арктики $(1,5,6)$.

В литературе есть упоминания всего о нескольких случаях искусственного осеменения в оленеводстве. Шотландские исследователи Н.М. Dott и M.N.P. Utsi представили данные по искусственному осеменению самок северного оленя свежей спермой $(9,10)$. М.Е. Мкртчян и В.И. Деряженцев в 1970-х годах опубликовали работы по оценке и криоконсервации спермы северных оленей (11-13). В 1990-е и 2000-е годы появились сообщения об искусственном осеменении криоконсервированной спермой (14-17). М.Е. Мкртчан с соавт. (18) были первыми в мире, кому удалось получить телят северных оленей после искусственного осеменения заморожено-оттаянной спермой. Однако методика криоконсервации спермы северных оленей до сих пор не разработана $(5,19)$.

Важная особенность адаптации организма оленей к условиям Арктики - прекращение сперматогенеза вне периода гона. Суровый арктический климат и короткий брачный сезон усложняют процедуру получение спермы у этих животных $(17,20,21)$.

Для разработки метода глубокой заморозки спермы северных оленей в рамках программы сохранения биологических ресурсов Арктики необходимо комплексное изучение процессов, происходящих в сперматозоидах под действием низких температур. Однако нет опубликованных данных об изменениях, происходящих со сперматозоидами этих животных при криоконсервации.

В представленной работе впервые охарактеризовано качество спермы северных оленей до и после замораживания. Показано, что наибольшим изменениям при криоконсервации подвергается двигательная активность половых клеток, а также целостность мембран. У северных оленей повышена доля сперматозоидов со сморщенной или отсутствующей акросомой. После замораживания эпидидимальные спермии сохраняют более высокую подвижность по сравнению с эякулированными, но при этом отмечается больше нарушений в характере их движения.

Целью нашего исследования была оценка изменения физиологических и морфологических показателей качества спермы северных оленей в процессе криоконсервации.

Методика. В опытах использовали сперму северных оленей (Rangifer tarandus) в возрасте от 1,5 до 7,5 лет, обитающих на полуострове Таймыр. От 11 особей сперму получали методом электроэякуляции (эякулятор DC100-240V, «Minitüb GmbH», Германия), не менее трех образцов от каждого. Также получали сперму из придатка семенника от двух самцов в возрасте 2,5 и 3,5 года, которые были кастрированы и оставлены в стаде для работ в упряжке, и от шести диких хоров (возраст от 1,5 лет) после отстрела (постмортальная оценка). Сперму получали автоматическими до- 
заторами после разреза придатка семенника и затем переливали в пробирки 1,5 мл с разбавителем Steridyl («Minitьb GmbH», Германия). Избегали попадания крови.

После оценки качества эякулированной и эпидидимальной спермы (объем, общая и прогрессивная подвижность и концентрация сперматозоидов) ее разбавляли в среде Steridyl до конечной концентрации 100 млн/мл, фасовали в соломинки по 0,25 мл и охлаждали до $5^{\circ} \mathrm{C}$ в течение 120 мин. После охлаждения и эквилибрации соломинки выдерживали в парах жидкого азота на поплавке при температуре $-110^{\circ} \mathrm{C}$ в течение 12 мин и затем опускали в жидкий азот. Размораживали образцы при $37^{\circ} \mathrm{C}$.

Концентрацию, общую и прогрессивную подвижность сперматозоидов определяли методом CASA (Computer-Assisted Semen Analysis) с помощью программы Аргус-CASA (OOO «Аргуссофт», Россия), морфологию и состояние акросом оценивали при фазово-контрастной световой микроскопии. Поврежденность плазматических мембран сперматозоидов изучали с использованием красителя Sperm VitalStain («Nidacon International AB», Швеция). Окрашивание проводили в пробирках типа Eppendorf (50 мкл спермы смешивали с 50 мкл красителя), готовили мазки на предметных стеклах. Препараты просматривали при увеличении $\times 1000$ с масляной иммерсией, подсчитывая не менее 200 клеток в каждом образце (белые клетки - неповрежденные, красные или розовые - сперматозоиды с поврежденными мембранами). Для визуализации применяли систему Аргус-CASA и микроскоп BA410 («Motic China Group Co. Ltd.», Китай).

Обработку данных проводили с использованием программ SigmaPlot 12.5 («Systat Software Inc.», США) и Micrisoft Excel.В статье приведены средние значения $(M)$, стандартные ошибки средних ( $\pm \mathrm{SEM})$, минимальные (min) и максимальные (max) значения показателей.

Результаты. В настоящее время есть множество данных о повреждениях сперматозоидов разных животных при криоконсервации $(22,23)$. В основном наблюдаются изменения подвижности и характера движения сперматозоидов, а также повреждения клеточных структур - хвостов, акросом и мембран. Повреждения клеток происходят в основном из-за образования кристаллов льда и осмотического стресса (24). Так, в сперме быков даже при оптимальных режимах охлаждения и оттаивания не переносят замораживание 40-50 \% клеток (25). В сперме лошадей наибольшие повреждения после криоконсервации наблюдались в области акросом (26). Сперма хряков обладает самой низкой криорезистентностью (23).

По нашим данным, средний объем эякулята северного оленя составил 0,5 $\pm 0,08$ мл, разница между эякулятами была от 0,02 до 2 мл, кон-

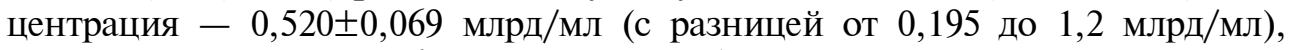
общая подвижность - 64,3土4,07 (10-84 \%), прогрессивная подвижность -

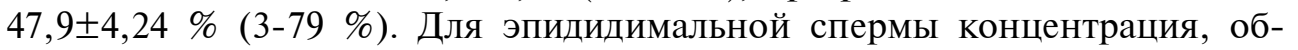
щая и прогрессивная подвижность сперматозоидов составляли соответ-

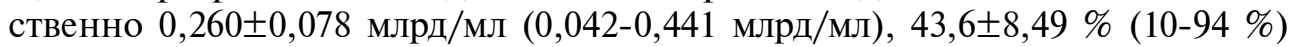
и 20,8土5,25 \% (3-45 \%). Эти результаты согласуются с данными зарубежных $(16,17)$ и советских исследователей $(13,18)$, а также с полученными нами ранее (20). Для криоконсервации отобрали 25 образцов спермы с общей подвижностью не менее $65 \%$.

Общая и прогрессивная подвижность сперматозоидов после оттаи-

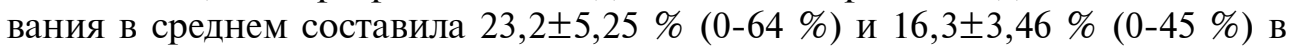

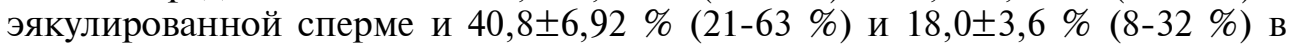
эпидидимальной сперме. Для сравнения - общая подвижность оттаянной спермы другого представителя семейства Оленевые - гривистого зомбара 
(Rusa timorensis) была от 7,5 до 39,8 \%, прогрессивная - от 2,5 до 14,7 \% (27). Авторы замораживали сперму, разбавленную в экстендере на основе Tris, близком по составу к использованному нами (Steridyl). В наших исследованиях общая подвижность сперматозоидов в оттаянной эякулированной сперме северных оленей была ниже, чем в эпидидимальной, прогрессивная подвижность почти не отличалась, а количество подвижных клеток, которые имели прямолинейно-поступательное движение, составляло соответственно 70 и 45 \%. A.F. Martínez c coавт. (28) отмечают, что хотя подвижность клеток эпидидимальной и эякулированной спермы оленей после криоконсервации не имеет больших различий, характер движения клеток лучше в эякулированной сперме.

Важный критерий при отборе спермы - определение количества нормальных (рис., А) и патологических форм сперматозоидов в эякуляте (25). Сперматозоиды могут быть повреждены быстрым охлаждением или низкой температурой (29). Патологическими считаются сперматозоиды с отклонениями в строении головки, шейки и хвоста. Существует несколько видов морфологических изменений акросомы. Мы фиксировали такие патологии, как частичная деформация внешней оболочки акросомы, разрывы и сморщивание наружной оболочки, отсутствие акросомы.

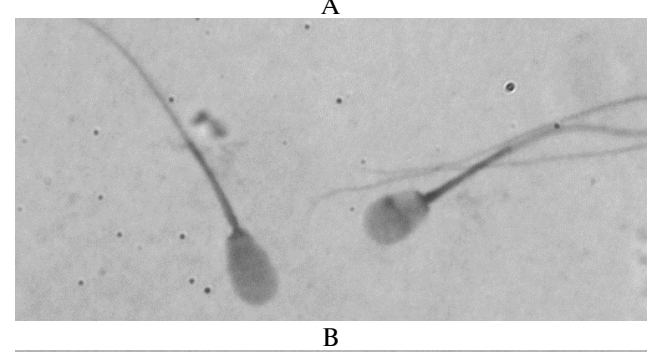

a

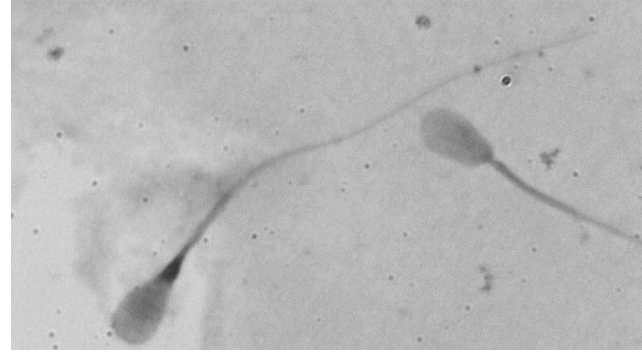

Б

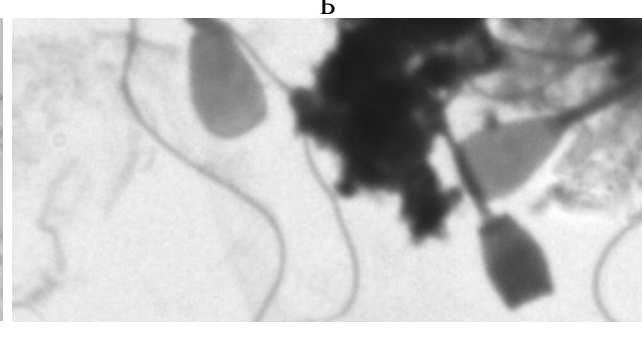

Сперматозоиды северного оленя (Rangifer tarandus), типичные для анализируемых образов: А - сперматозоиды нормальной формы, Б - сперматозоиды со сморщенной и отсутствующей акросомой, В - сперматозоиды с повреждениями шейки. Фазовый контраст, увеличение $\times 1000$, микроскоп ВА410 («Motic China Group Co. Ltd.», Китай), визуализирующая система Аргус-CASA (OOO «Аргуссофт», Россия).

Как в эякулированной, так и в эпидидимальной сперме северных оленей наблюдалась повышенная доля сперматозоидов со сморщенной или отсутствующей акросомой (см. рис., Б) по сравнению с другими ви-

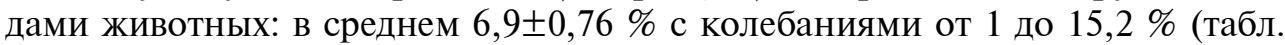
2). Возможно, это особенность спермы северных оленей. Следует отметить, что после замораживания не наблюдалось значительного увеличения числа клеток с повреждениями акросом (в среднем 10,1 $\pm 0,78$ \% с колебаниями от 3,6 до 18,3 \%). Количество клеток с повреждениями в области хвоста (см. рис., В) составило в среднем $11,9 \pm 1,31 \%(1,6-33,2 \%)$ до замораживания и $15,5 \pm 1,15 \%(5,0-34,4 \%)$ после оттаивания.

Целостность мембраны - необходимое условие для функционирования клеток. В свежей (эякулированной и эпидидимальной) сперме се-

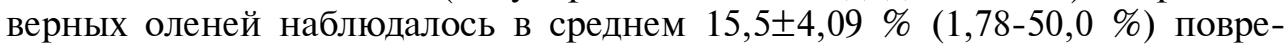
ждений мембран, в заморожено-оттаянной - 21,8土4,44 \% (3,5-53,3\%).

По изменению подвижности сперматозоидов после криоконсервации эякуляты заметно различались. Общая подвижность в среднем снизи- 


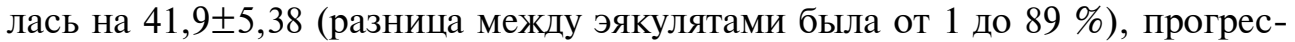
сивная подвижность - на 36,8土5,29 \% (0 до $75 \%$ ). Сперматозоиды в $42 \%$ эякулятов теряли при криоконсервации более $50 \%$ общей подвижности, в $25 \%$ эякулятов - менее $20 \%$ подвижности. В части образцов наблюдалась полная потеря подвижности после замораживания, в некоторых случаях изменения были незначительными. Такая большая вариабельность обусловлена как особенностями криорезистентности спермы оленей, так и различиями между особями. Значительную индивидуальную изменчивость по подвижности клеток после оттаивания отмечают и у благородного оленя (30).

Заметного увеличения частоты повреждений в области хвоста и шейки сперматозоидов и акросом мы не наблюдали. Количество клеток с повреждениями хвоста и шейки увеличилось в среднем на 4,2 $\pm 1,05 \%(0,01-$

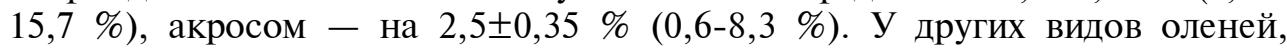
например у благородного оленя, число поврежденных акросом после замораживания-оттаивания увеличивалось в среднем на $20 \%$ (31). В сперме жеребцов количество сперматозоидов с гипоплазией акросомы и отсутствием внутреннего содержимого после криоконсервации увеличивалось на $20,9 \%$, а с деградацией акросомы - на 10,4 \% (32). В работах по изучению влияние криоконсервации и оттаивания на сперму благородного оленя авторы отмечают индивидуальную изменчивость между самцами по сохранности целостности мембран и акросом $(33,34)$.

В наших исследованиях также наблюдалась высокая изменчивость между образцами по подверженности повреждениям плазматических мембран сперматозоидов. В среднем повреждения увеличились на 10,9 $\pm 5,02 \%$ $(0,13$ до $45 \%)$. Это подтверждает теорию о том, что в сперматозоидах северного оленя мембраны наиболее чувствительны к действию низких температур, что сказывается и на подвижности клеток. Достоверной разницы по изменениям морфологических показателей качества спермы северных оленей после криоконсервации между эякулированной и эпидидимальной спермой не выявили. Отметим, что сперма сохраняет оплодотворяющую способность, несмотря на резкие снижения подвижности сперматозоидов после оттаивания. Так, в результате оплодотворения in vitro яйцеклеток северного оленя оттаянной эпидидимальной спермой одного из самцов в выборке с подвижностью сперматозоидов, сниженной после криоконсервации более чем на 50 \% (с 96 до 40 \%), нами получены эмбрионы на стадии бластоцисты (данные не представлены).

Таким образом, наибольшим изменениям при криоконсервации спермы северного оленя подвергается двигательная активность клеток и целостность мембран. В свежеполученных эякулятах концентрация спер-

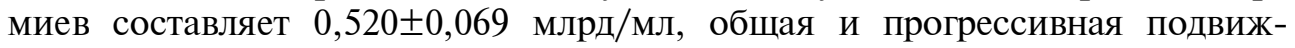

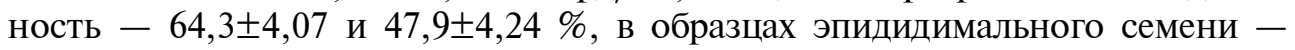

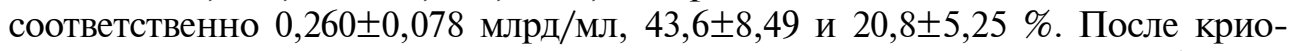

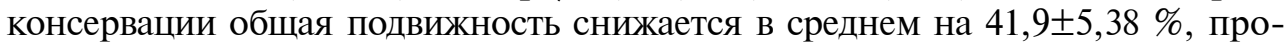
грессивная - на $36,8 \pm 5,29 \%$. Частота повреждений плазматических мем-

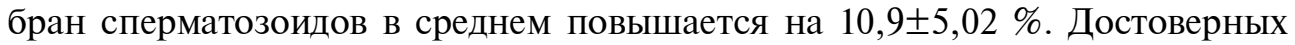
различий по изменениям физиологических и морфологических показателей качества спермы при замораживании и оттаивании между эякулированной и эпидидимальной спермой не выявлено. Однако после криоконсервации наблюдается высокая индивидуальная изменчивость по всем показателям качества спермы. Полученные данные по изменениям физиологических и морфологических показателей качества спермы северного оленя после замораживания и оттаивания расширяют представления о репродуктивной биологии этого вида. Выявленные особенности также следует 


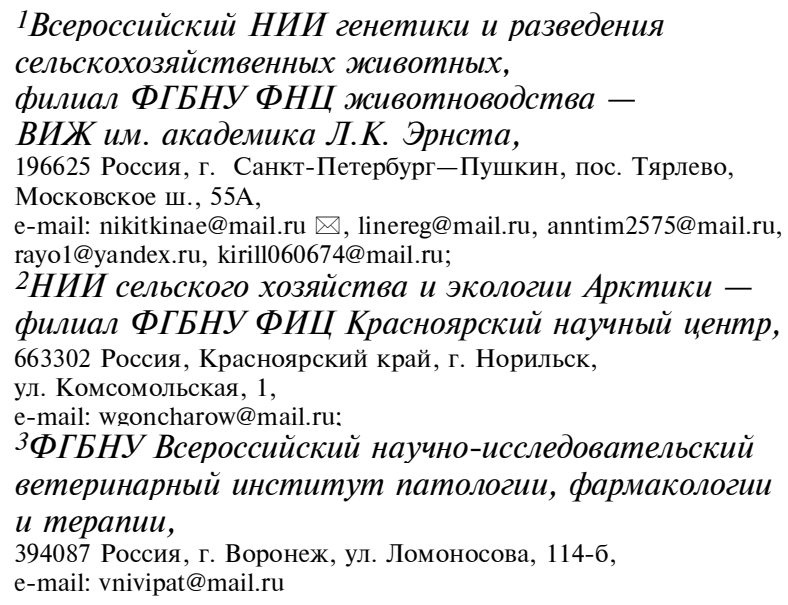

Поступила в редакцию 22 августа 2019 года

Sel'skokhozyaistvennaya biologiya [Agricultural Biology], 2019, V. 54, № 6, pp. 1188-1195

\title{
CHANGE OF PHYSIOLOGICAL AND MORPHOLOGICAL SPERM QUALITY TRAITS IN REINDEER (Rangifer tarandus) DURING CRYOPRESERVATION
}

\author{
E.V. Nikitkina ${ }^{1}$, A.A. Musidray', A.A. Krutikova1, S.V. Timofeeva' ${ }^{1}$, K.V. Plemyashov', \\ V.V. Goncharov', S.V. Shabunin ${ }^{3}$
}

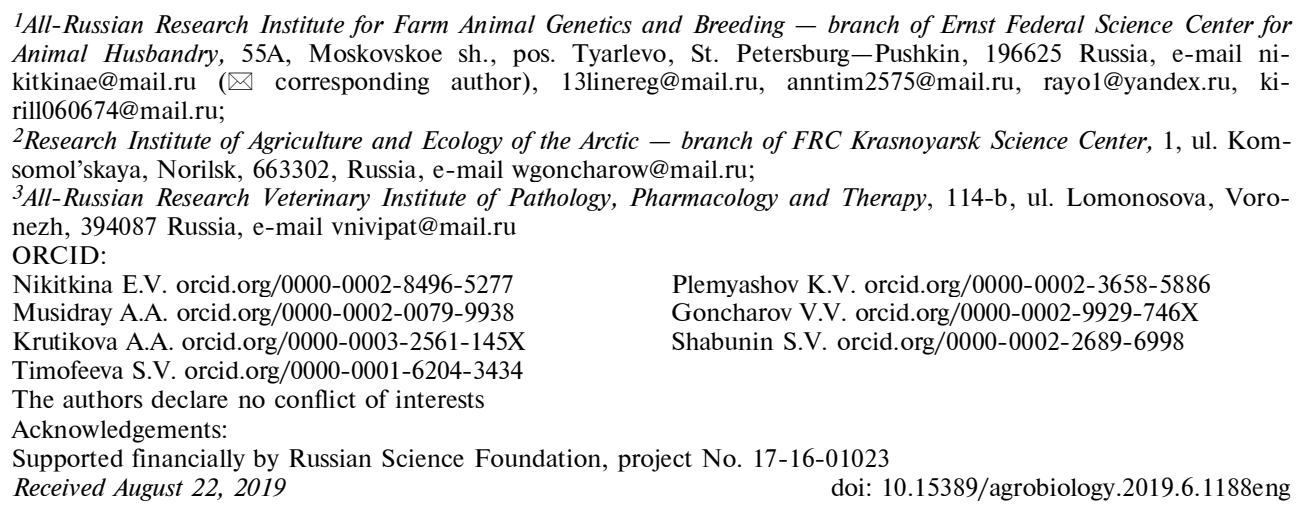

\section{Abstract}

Assisted reproductive technologies allow effective preservation and use of endangered animal gene pool and creation of new breeding forms. In reindeer (Rangifer tarandus) herding, the technique of sperm cryopreservation is still under development. This is due to the difficulty of collecting reindeer sperm in the Arctic conditions. Besides, the rutting season of reindeer begins in the autumn and lasts about a month. Only during this period is it possible to collect sperm as spermatogenesis in reindeer stops after rutting season. The aim of the work was to study the effects of cooling and freezing-thawing on the physiological and morphological traits of reindeer sperm quality. Reindeer sperm was collected by electric ejaculator or by washing out of the epididymis. After assessing the quality of ejaculated and epididymal semen (volume, total and progressive motility and sperm concentration), the sperm was diluted with Steridyl medium to a final concentration of 100 million/ml, packed in $0.25 \mathrm{ml}$ straws and cooled to $5{ }^{\circ} \mathrm{C}$ for $120 \mathrm{~min}$. After cooling and balancing, the straws were kept in liquid nitrogen vapors on a float at $-110^{\circ} \mathrm{C}$ for $12 \mathrm{~min}$ and then lowered into liquid nitrogen. Semen was thawed at $37{ }^{\circ} \mathrm{C}$. The initial assessment of ejaculated sperm showed that the average volume of reindeer ejaculate was $0.5 \pm 0.08 \mathrm{ml}$, with concentration of $0.520 \pm 0.069$ billion/ml, total motility of $64.3 \pm 4.07 \%$, and progressive motility of $47.9 \pm 4.24 \%$. The epididymal sperm cell concentration was on average $0.260 \pm 0.078$ billion/ $\mathrm{ml}$, total and progressive motility was $43.6 \pm 8.49 \%$ and $20.8 \pm 5.25 \%$, respectively. There was a large variability between ejaculates on the extent of changes in sperm motility after cryopreservation. Thus, total motility decreased by 
$41.9 \pm 5.38 \%$ on average with fluctuations from $1 \%$ to $89 \%$, progressive - by $36.8 \pm 5.29 \%$ with fluctuations from $0 \%$ to $75 \%$. A total of $42 \%$ of ejaculates lost more than $50 \%$ total motility. In some cases, there was a complete loss of motility after freezing, and in some samples the changes were insignificant. Large variability in changing cell motility was observed both in ejaculated and in epididymal semen. Epididymal sperm cells had higher motility after freezing than ejaculated spermatozoa, but showed more pronounced disturbances in the motility character. Sperm morphology analysis showed that there is an increased percentage with wrinkled or missing acrosome as compared to other animal species, i.e. $6.9 \pm 0.76 \%$ in both ejaculated and epididymal reindeer sperm cells. There was no significant increase in damages of the sperm tail, neck and acrosome. The number of cells with injuries in tail and neck increased by $4.2 \pm 1.05 \%$ with a range from $0.01 \%$ to $15.7 \%$, and acrosome - by $2.5 \pm 0.35$ with a range from $0.6 \%$ to $8.3 \%$. High variability in the increase of plasma membrane damages was observed, i.e. $10.9 \pm 5.02 \%$ with fluctuations from $0.13 \%$ to $45 \%$. Such a large variability is due to the peculiarities of the reindeer sperm cryoresistance and differences between individual ejaculates. Significant difference in physiological and morphological changes in semen quality after cryopreservation between ejaculated and epididymal sperm were not found. Thus, the greatest changes in the cryopreserved reindeer semen are in motility and membrane integrity. The obtained data on physiological and morphological changes in reindeer semen during freezing should be taken into account when optimizing the composition of diluents and cryopreservation protocol.

Keywords: Rangifer tarandus, reindeer, cryopreservation, sperm motility, acrosomes, cell membranes.

\section{R E F E R E N C ES}

1. Laishev K.A., Samandas A.M., Prokudin A.V., Romanenko T.M., Goncharov V.V., Mukhamadeeva T.V. Dostizheniya nauki i tekhniki APK, 2013, 11: 42-44 (in Russ.).

2. Goncharov V.V., Nikitkina E.V. Genetika i razvedenie zhivotnykh, 2016, 2: 3-7 (in Russ.).

3. Holand $\varnothing$., Røed K.H., Mysterud A., Kumpula J., Nieminen M., Smith M.E. Effect of male composition during rut on reproduction and reproductive parameters in reindeer (Rangifer tarandus tarandus). Journal of Wildlife Management, 2003, 67: 25-33.

4. Holand $\varnothing .$, Gjøstein H., Losvar A., Kumpula J., Smith M.E., Røed K.H., Nieminen M., Weladji R.B. Social rank in female reindeer (Rangifer tarandus): effects of body mass, antler size and age. Journal of Zoology, 2004, 263(4): 365-372 (doi: 10.1017/S0952836904005382).

5. Ropstad E., Veiberg V., Säkkinen H., Dahl E., Kindahl H., Holand O., Beckers J.F., Eloranta E. Endocrinology of pregnancy and early pregnancy detection by reproductive hormones in reindeer (Rangifer tarandus tarandus). Theriogenology, 2005, 63(6): 1775-1788 (doi: 10.1016/j.theriogenology.2004.08.003).

6. Nikitkina E.V., Goncharov V.V., Krutikova A.A., Sergeeva O.K., Musidrai A.A., Plemyashov K.V. Genetika i razvedenie zhivotnykh, 2017, 1: 9-14 (in Russ.).

7. Garde J.J., Martínez-Pastor F., Gomendio M., Malo A.F., Soler A.J., Fernández-Santos M.R., Esteso M.C., García A.J., Anel L., Roldán E.R.. The application of reproductive technologies to natural populations of red deer. Reproduction in Domestic Animals, 2006, 41(Suppl. 2): 93-102 (doi: 10.1111/j.1439-0531.2006.00773.x).

8. Lindeberg H., Aalto J., Amstislavsky S., Järvinen M., Piltti K., Oksman M., Korhonen H., Vahtiala S., Eloranta E., Pudas T., Nieminen M., Helin A., Reinikainen E., Valtonen M. Development of assisted reproductive technology in the farmed European polecat (Mustela putorius) and in the semi-domesticated reindeer (Rangifer tarandus tarandus). Extended Abstracts of the 28th Congress of the International Union of Game Biologist. Hannover, Germany, 2005: 240-241.

9. Dott H.M., Utsi M.N.P. Artificial insemination in reindeer (Rangifer tarandus). Journal of Zoology, 1973, 170(4): 505-508 (doi: 10.1111/j.1469-7998.1973.tb05065.x).

10. Dott H.M., Utsi M.N.P. The collection and examination of semen of the reindeer (Rangifer tarandus). Journal of Zoology, 1971, 164(4): 419-424 (doi: 10.1111/j.1469-7998.1971.tb01325.x).

11. Deryazhentsev V.I. V sbornike: Trudy Magadanskogo zonal'nogo nauchno-issledovatel'skogo instituta sel'skogo khozyaistva Severo-Vostoka [In: Proceedings of the Magadan Zonal Research Institute of Agriculture of the North-East]. Magadan, 1974, tom 4: 30-35 (in Russ.).

12. Mkrtchyan M.E., Deryazhentsev V.I. V: Sb. nauchnykh rabot Murmanskoi olenevodcheskoi opytnoi stantsii [In: Collection of scientific papers of the Murmansk reindeer herding experimental station]. Murmansk, 1973, tom 2: 34-36 (in Russ.).

13. Mkrtchan M.E., Deryazhentsev V.I. V: Sb. nauchnykh rabot Murmanskoi olenevodcheskoi opytnoi stantsii [In: Collection of scientific papers of the Murmansk reindeer herding experimental station]. Murmansk, 1973, tom 2: 31-33 (in Russ.).

14. Lindeberg H., Valtonen M. Ex-situ preservation of endangered species as frozen gametes and embryos. Programme and abstracts of the 10th Nordic Conference on Reindeer Research, 13.15.3.1998, Kautokeino, Norway. R.E. Haugerud (ed.). Rangifer, 1998, 18(6): 97-98 (doi: 
10.7557/2.18.6.1372).

15. Vahtiala S., Lindeberg H., Eloranta E., Säkkinen H. Intrauterine artificial insemination in the reindeer. Programme and abstracts - 11th Arctic Ungulate Conference, 24-28 August 2003, Saariselkä, Finland.R.E. Haugerud (ed.). Rangifer, 2003, 23(3): 67 (doi: 10.7557/2.23.3.1645).

16. Lindeberg H., Oksman M., Järvinen M., Eloranta E., Vahtiala S., Valtonen M. Semen collection in the reindeer (Rangifer tarandus tarandus). In: Book of abstracts for the XII Post Graduate Symposium of Animal Physiology, Research Station of Oulanka, Oulanka, Finland, 7.-9. September 2000. S. Saarela, E. Hohtola (eds.). University of Oulu, 2000, 6: 12.

17. Shipka M.P., Rowell J.E., Bychawski S. Artificial insemination in reindeer using frozen-thawed semen. Animal Science, 2010, 88(E-Suppl. 2): 124. Abstract M327.

18. Mkrtchyan M.E., Rombe S.M. Zhivotnovodstvo, 1973: 72-74 (in Russ.).

19. Plemyashov K., Nikitkina E., Krutikova A., Timofeeva S., Shiryaev G., Musidray A., Goncharov V. Semen collection, evaluation and freezing in reindeer (Rangifer tarandus). Animal Reproduction Science, 2018, 194: e13-e14 (doi: 10.1016/j.anireprosci.2018.04.032).

20. Plemyashov K., Nikitkina E., Lindeberg H., Holand O., Krutikova A., Timofeeva S., Shiryaev G., Musidrai A. Basic semen evaluation in reindeer (Rangifer tarandus). Poster Presentations. Reproduction in Domestic Animals, 2018, 53(S2): 183 (doi: 10.1111/rda.13272).

21. Musidrai A., Plemyashov K., Nechaev A., Nikitkina E., Krutikova A., Timofeeva S., Shiryaev G., Kudinov A., Polteva E., Goncharov V. Analysis of fixing methods of reindeer (Rangifer tarandus) for semen collection. Poster Presentations. Reproduction in Domestic Animals, 2018, 53(S2): 170 (doi: 10.1111/rda.13272).

22. Büyükleblebici S., Tuncerb P.B., Bucak M.N., Ekend A., Sarı̈zkan S., Taşdemir U., Endirlik B.Ü. Cryopreservation of bull sperm: Effects of extender supplemented with different cryoprotectants andantioxidants on sperm motility, antioxidant capacity and fertility results. Animal Reproduction Science, 2014, 150(3-4): 77-83 (doi: 10.1016/j.anireprosci.2014.09.006).

23. Pezo F., Romero F., Zambrano F., Sánchez R.S. Preservation of boar semen: an update. Reproduction of Domestic Animals, 2019, 54(3): 423-434 (doi.org/10.1111/rda.13389).

24. Rodriguez-Martinez H., Wallgren M. Advances in boar semen cryopreservation. Veterinary Medicine International, 2011, 2011: Article ID 396181 (doi: 10.4061/2011/396181).

25. Grötter L.G., Cattaneo L., Marini P.E., Kjelland M.E., Ferré L.B. Recent advances in bovine sperm cryopreservation techniques with a focus on sperm post-thaw quality optimization. Reproduction in Domestic Animals, 2019, 54(4): 655-665 (doi: 10.1111/rda.13409).

26. Atroshchenko M.M., Kalashnikov V.V., Bragina E.E., Zaitsev A.M. Comparative study of the structural integrity of spermatozoa in epididymal, ejaculated and cryopreserved semen of stallions. Agricultural Biology [Sel'skokhozyaistvennaya Biologiya], 2017, 52(2): 274-281 (doi: 10.15389/agrobiology.2017.2.274eng).

27. Monaco D., Zappia E., Apichaya S., Lacalandra G.M., Thongtip N. Post-thawing effects of three cryopreservation diluents on Rusa deer (Rusa timorensis) spermatozoa. Reproduction in Domestic Animals, 2019, 54(3): 635-638 (doi: 10.1111/rda.13380).

28. Martínez A.F., Martínez-Pastor F., Álvarez M., Fernández-Santos M.R., Esteso M.C., de Paz P., Garde J.J., Anel L. Sperm parameters on Iberian red deer: electroejaculation and post-mortem collection. Theriogenology, 2008, 70(2): 216-226 (doi: 10.1016/j.theriogenology.2008.04.001).

29. Gao D.Y., Critser J.K. Mechanisms of cryoinjury in living cells. ILAR Journal, 2000, 41(4): 187-196 (doi: 10.1093/ilar.41.4.187).

30. García-Álvarez O., Soler A.J., Maulen Z., Maroto-Morales A., Iniesta-Cuerda M., MartínMaestro A., Fernández-Santos M.R., Garde J.J. Selection of red deer spermatozoa with different cryoresistance using density gradients. Reproduction in Domestic Animals, 2016, 51: 895-900 (doi: 10.1111/rda.12755).

31. Esteso M.C., Fernández-Santos M.R., Soler A.J., Montoro V., Quintero-Moreno A., Garde J.J. The effects of cryopreservation on the morphometric dimensions of Iberian red deer (Cervus elaphus hispanicus) epididymal sperm heads. Reproduction in Domestic Animals, 2006, 41(3): 241246 (doi: 10.1111/j.1439-0531.2006.00676.x).

32. Atroshchenko M.M., Bragina E.E., Zaitsev A.M., Kalashnikov V.V., Naumenkova V.A., Kudlaeva A.M., Nikitkina E.V. Conservation of genetic resources in horse breeding and major structural damages of sperm during semen cryopreservation in stallion. Nature Conservation Research, 2019, 4(Suppl. 2): 78-82 (doi: 10.24189/ncr.2019.024).

33. Soler A.J., García A.J., Fernández-Santos M.R., Esteso M.C., Garde J.J. Effects of thawing procedure on postthawed in vitro viability and in vivo fertility of red deer epididymal spermatozoa cryopreserved at $-196{ }^{\circ} \mathrm{C}$. Journal of Andrology, 2003, 24(5): 746-756 (doi: 10.1002/j.19394640.2003.tb02737.x).

34. Zomborszky Z., Nagy S., Nánássy L., Szabari M., Body S. Experiences in deer sperm cryopreservation under practical conditions - a pilot study. Animal Reproduction Science, 2005, 90(1-2): 185-190 (doi: 10.1016/j.anireprosci.2005.01.014). 